\title{
A comparative study of the effect of diet and soda carbonated drinks on the histology of the cerebellum of adult female albino Wistar rats
}

Eluwa $\mathrm{MA}^{1}$, Inyangmme $\mathrm{II}^{1}$, Akpantah $\mathrm{AO}^{1}$, Ekanem $\mathrm{TB}^{1}$, ${ }^{*}$ Ekong $\mathrm{MB}^{2}$, Asuquo $\mathrm{OR}^{1}$, Nwakanma $\mathrm{AA}^{3}$

1. Department of Anatomy, Faculty of Basic Medical Sciences, University of Calabar, Calabar, Nigeria

2. Department of Anatomy, Faculty of Basic Medical Sciences, University of Uyo, Uyo, Nigeria

3. Department of Anatomy, Faculty of Basic Medical Sciences, Anambra State University, Uli, Nigeria

\begin{abstract}
Background: Carbonated drinks are widely consumed because of their taste and their ability to refresh and quench thirst. These carbonated drinks also exist in the form of diet drinks, for example Diet Coke ${ }^{\circledR}$, Pepsi $\AA$, extra.

Objectives: A comparative effect of the diet and regular soda carbonated drinks on the histology of the cerebellum of female albino Wistar rats was investigated.

Methods: Fifteen adult female Wistar rats weighing between 180-200g were divided into 3 groups; designated as groups A, $\mathrm{B}$ and $\mathrm{C}$, and each group consisted of five rats. Group A was the Control group and received distilled water, while groups $B$ and $C$ were the experimental groups. Group $B$ was administered $50 \mathrm{ml}$ of regular soda (RS), and group $C$ was administered $50 \mathrm{ml}$ of diet soda (DS) each per day for 21 days, and the rats were sacrificed on Day 22, and their cerebellums excised and preserved.
\end{abstract}

Results: Histological result of the sections of the cerebellum showed shrunken and degenerated Purkinje cells with hypertrophied dendrites, especially in the DS group, which was less in the RS group compared to the control group.

Conclusions: These results suggest that diet soda has adverse effect on the cerebellum of adult female albino Wistar rats. Key words: Carbonated drink, Diet soda, regular soda, Cerebellum, Wistar rats

African Health Sciences 2013; 13(3): 541 - 545 http://dx.doi.org/10.4314/ahs.v13i3.1

\section{Introduction}

Carbonated drinks elicit a sensation that is highly sought after, yet the underlying neural mechanisms are ill defined. Carbonated drinks could be soft or hard, depending on the absence or presence of alcohol respectively. Soft drinks could be regarded as regular or diet depending on the sweetening agent. Sugar is used as sweeteners in regular soft drinks, and it has been reported to result in obesity upon consumption $^{1,2}$.

Diet coke ${ }^{\circledR}$ (DC) on the other hand is a non-caloric beverage that is sweetened with aspartame, except for the splendor-sweetened version, which is sweetened with both splendor, or sucralose, and acesulfame potassium, and which is also known as Ace $\mathrm{K}^{3,4}$. These sweeteners in diet

\author{
*Corresponding author: \\ Moses B Ekong \\ Department of Anatomy \\ Faculty of Basic Medical Sciences \\ University of Uyo \\ Uyo, Nigeria \\ Tel: +2348030868505 \\ E-mail: mbe_flashpoint@yahoo.com
}

coke are non-nutritive and non-caloric. DC also contains caffeine, depending on the quantities consumed $^{5}$. Caffeine is linked to anxiety and sleep disruption when consumed in excess ${ }^{6}$.

Aspartame as contained in DC is hydrolyzed in the intestine to its components; aspartic acid, methanol and phenylalanine ${ }^{7}$. Each of these components is toxic and affects different body organs including the central nervous system. About fifty per cent of aspartame is made up by phenylalanine, which could cross the blood-brain barrier and act as a precursor of catecholamine in the brain, as well as leading to phenylketonuria. Forty per cent of aspartame is composed of aspartic acid, an excitotoxin that contributes to free radical damage in the brain. Methanol which forms $10 \%$ of the byproducts of aspartame is a toxic compound converted in the liver to formaldehyde that is neurotoxic and carcinogenic ${ }^{7}$.

Reports on the effects of aspartame in body cells is controversial; while ${ }^{8}$ links brain tumors to worldwide Aspartame use, ${ }^{9}$ showed that Aspartame consumption might result in seizures, memory loss, dizziness, headache and behavioural changes. A more 
recent study reported non-association between aspartame and cancer in any tissue and, indicating that aspartame is safe for consumption ${ }^{10,11}$.

As most of the previous studies were concerned about the effect of aspartame on memory, learning and behavioral changes, this study investigates the effect of aspartame and nonaspartame products on the histology of the cerebellar cortex of adult female albino Wistar rats.

\section{Methods}

Fifteen (15) adult female albino Wistar rats were breed in the animal house of the Department of Human Anatomy, University of Calabar, Calabar. The animals were fed with normal rat chow and water was provided ad libitum throughout except during the treatment period. The animals were divided into three group designated $\mathrm{A}, \mathrm{B}$ and $\mathrm{C}$, each consisting of five rats. Group A animals were the control and groups $\mathrm{B}$ and $\mathrm{C}$ were the experimental animals.

Experimental protocol

The rats weighed between 180-200g before the commencement of the experiment. $50 \mathrm{mls}$ each of Regular soda, RS (coke) and Diet soda, DS (coke), were administered daily to groups B and C respectively. The quantities of beverages consumed by the rats were measured daily and were replaced the next day. The control group received distilled water. All administrations were by oral gavages.

The administration lasted for 21 days, and the animals were sacrificed by chloroform inhalation on day 22. Each animal's brain was excised after dissection of the skull, and preserved using 10\% buffered formalin. Following complete fixation of the whole brain, the cerebellum was excised. Routine histological processing was carried out and staining was done using the haematoxylin and Eosin technique.

On staining the slides were mounted on a light microscope and a low power magnification (x100) and a high power magnification (x400) were observed, and photomicrographs were made by means of a Bresser LCD Microscope (Meade Instruments Europe, Germany) linked to a computer.

\section{Results}

\section{Observation}

The DS group consumed less than $20 \mathrm{mls}$ of the diet soda each day (about 3-24ml of the diet coke), while the RS group consumed almost all $50 \mathrm{mls}$ of regular soda each day (about $32-50 \mathrm{ml}$ of regular coke)

\section{Histological observation}

Group A (Control): The section of the cerebellum showed the normal histology of the cerebellum and its layers: the outer cerebellar cortex and inner medulla. The cerebellar cortex presented three layers; the outer molecular, intermediate Purkinje and inner granular, layers. In the molecular layer were sparsely distributed cells. The Purkinje cell layer, which is onecell thick, showed large pyriform shaped Purkinje cells with deeply stained basophilic nucleus. The granular layer presented numerous, thickly populated cells (figure 1a \& 2a).

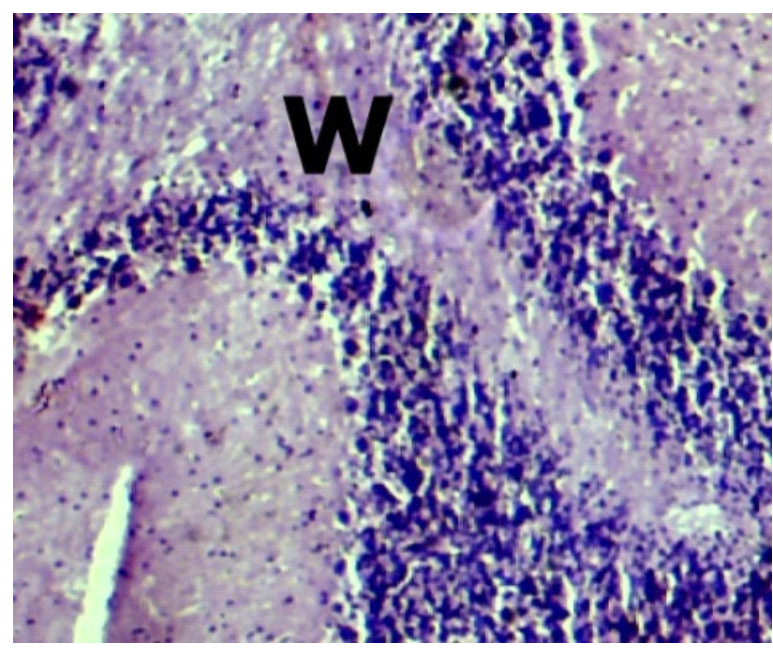

Figure 1 (a) : Control cerebellum showing its three distinct layers and white matter (W)

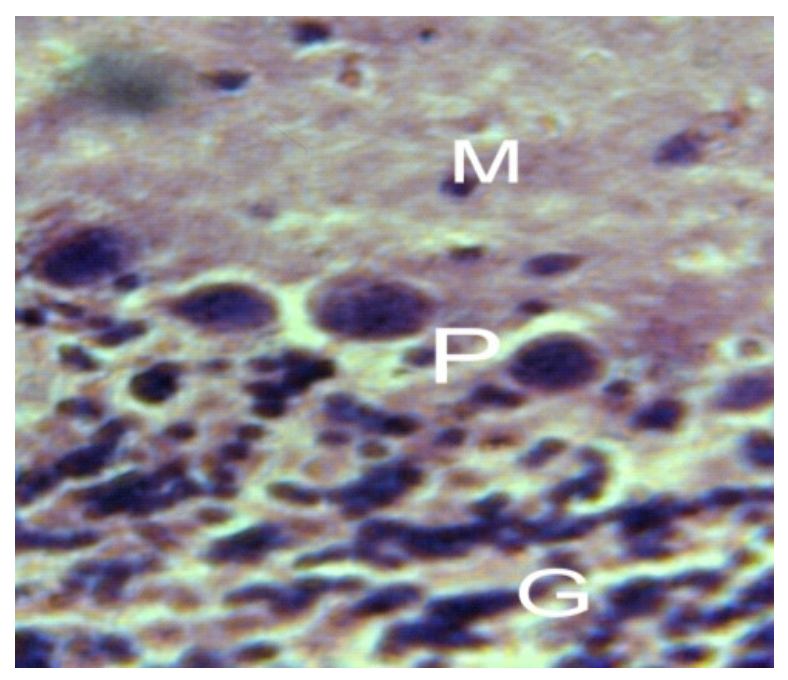

Figure 2 (a): Control cerebellum showing three distinct layers.

The molecular layer containing few nerve cells (M), the purkinje cells layer containing a monolayer of Purkinje cells $(\mathrm{P})$, the granular layers consisting of densely -packed granular cells. 
Group B (RS): The histological sections of the cerebellum of the RS group showed vacuolations (spongiosis) between cells fibers of the white matter (Figure 1b). The cellular arrangement of the cerebellar cortex presented the three layers showing loss and slightly degenerated Purkinje cells, and hyperplasia of the cells in the molecular and granular layers (Figures 1b \& 2b).

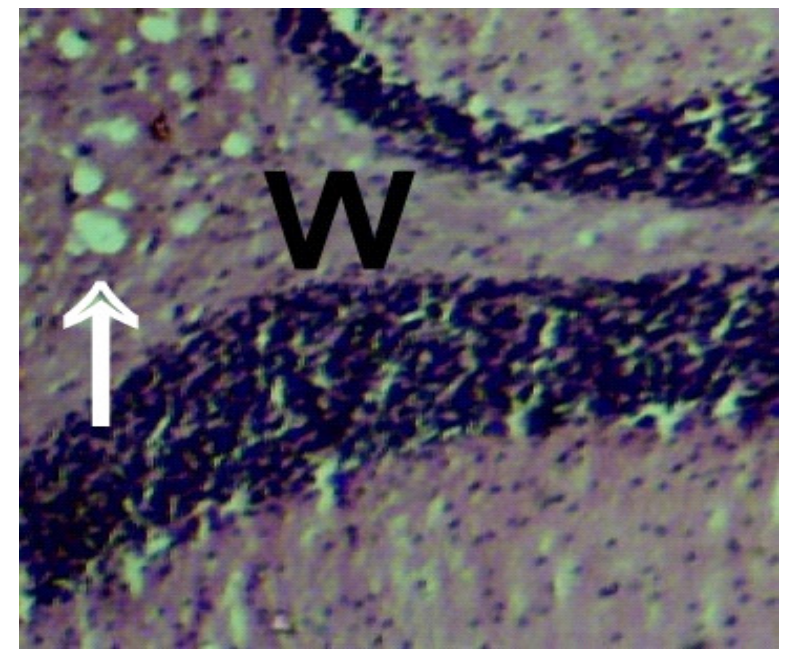

Figure 1 (b): Cerebellum- 50mls of Regular Coke showing Vacuolations (spongiosis) in its white matter (W)

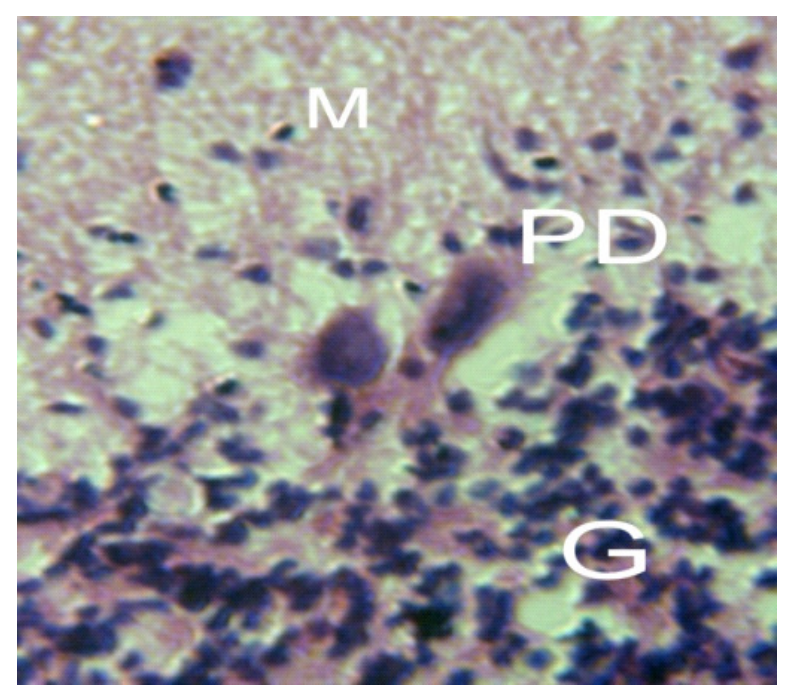

Figure 2 (b): Cerebellum - 50mls of Regular coke showing increase in the number of cells in the molecular (M) and the granular layers (G), loss and slight degeneration of Purkinje cells (PD)
Group C (DS): The histological sections of the cerebellum of the DS group showed Purkinje cells with prominent hypertrophied dendrites (Figure 2c). Halo of empty spaces appeared around the Purkinje cells. The cells of molecular layer appeared hypertrophied with enlarged stellate and basket cells (Figures 1c \& 2c).

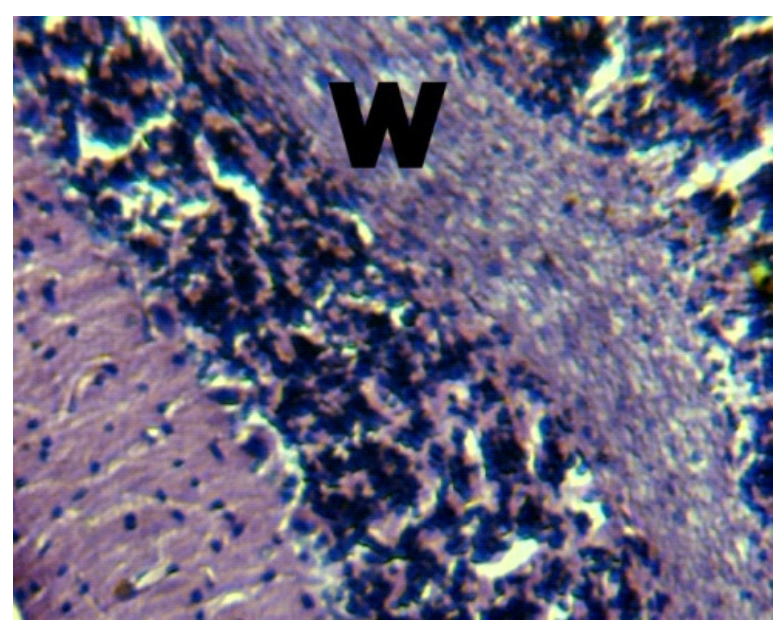

Figure 1 (c): Cerebellum- 50mls of Diet Coke showing its white matter (W) with no vacuolations in it.

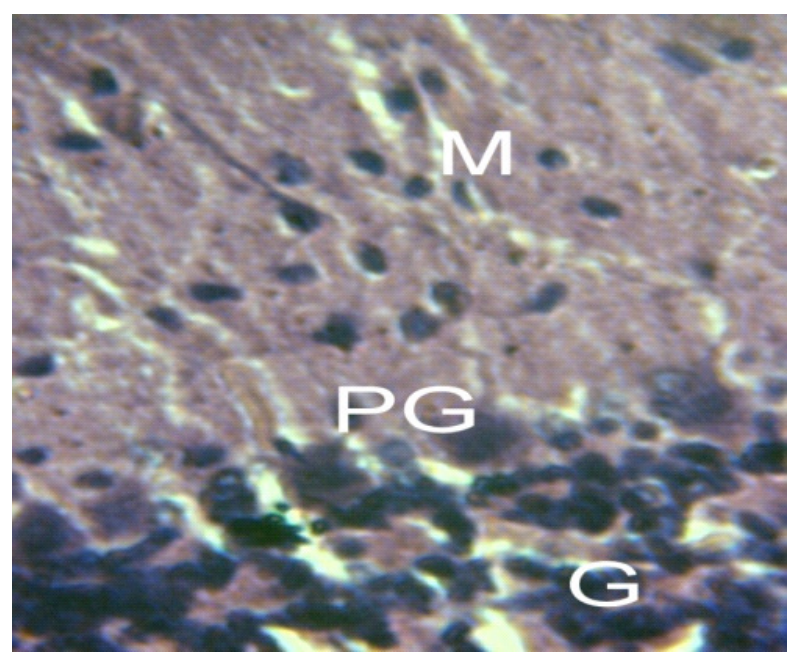

Figure 2 (c): Cerebellum - 50mls of diet coke showing hypertrophy, elongation and increased molecular (M) cells and granular cells (G), degeneration and increase in number of Purkinje cells (PG).

Figure 1 (a-c): Photomicrographs of cerebellum of control and treated groups which received $50 \mathrm{mls}$ of Regular coke and diet coke (H \& E X 100 for all Figures).

Figure 2: Photomicrographs of cerebellum of control and treated groups which received $50 \mathrm{mls}$ 
of Regular coke and diet coke (H \& E X 400 for all Figures).

\section{Discussion}

In this study, the Diet soda (DS) group revealed shrunken and degenerated Purkinje cells with hypertrophied dendrites. The Purkinje cells are the only cerebellar efferent neurons ${ }^{12}$. These alterations in the shape of the Purkinje cells may lead to inadequate signals from the cerebellum to higher centres, a possible non motor coordination function.

DS contains caffeine and aspartame. Caffeine is linked to anxiety and sleep disruption when consumed in excess ${ }^{6}$. These symptoms may be due to disruption of the physiological or/and anatomical role of the brain areas involved in this function. Aspartame on the other hand has been linked to seizures, memory loss, dizziness, headache and behavioural changes?. These may be directly or through its constituents; aspartic acid, phenylalanine and methanol.

Aspartic acid is an excitatory neurotransmitter in the central nervous system. It acts by increasing the depolarization at the postsynaptic membrane. This might cause rapid firing of the neurons ${ }^{12}$. Increased level of these substances could change the activity of the brain and alter its normal functioning ${ }^{13}$.

Olney et $a l .^{8}$ reported that aspartic acid caused excessive stimulation of the excitatory glutamate receptors leading to their hypertrophy and eventually hyperplasia. As glutamate is a constituent of this soda, this may have been a reason for the changes observed in this study.

Phenylalanine decreased catecholamines neurotransmitter level ${ }^{12,14}$. Methanol has been reported to cause an increase in the metabolizing enzymes of the cerebellum as well as other sites in rat brain ${ }^{15}$.

Pan et al. ${ }^{16}$ reported apoptotic Purkinje cells with increased number of cells in the molecular layer of aspartame treated animals. Glutamate is a neurotransmitter which sends excitatory signals in the cerebellum ${ }^{17}$.

Furthermore, it was observed that the DS group consumed less than $20 \mathrm{mls}$ of the drink showing the significantly (at $\mathrm{p}<0.05)$ lowest consumption as compared to the RS group which had the significantly (at $\mathrm{p}<0.05$ ) highest consumption. This could be due to their loss of appetite.

Vacuolations found principally in the white matter of the RS group can be attributed to the loss of cellular components of the tissue or organ. This is in line with the work done by Llinas et al. ${ }^{18}$ who reported increased vacuolation and loss of Purkinje cells. The hypertrophy of stellate and basket cells of the molecular layer, and that of the granular layer observed in the DS group may also be due to excessive excitation of these cells. This is in line with a report that the excitotoxins acting at different sites within the central nervous system could strip myelin from fibers and destroying neurons ${ }^{19}$.

Lutsey et al. ${ }^{20}$ reported that consuming just a can of diet soda increases one's risk of developing metabolic syndrome. Abeer ${ }^{21}$ reported aspartame resulted in the loss of the pyriform shape of Purkinje cells, condensed nuclei with affected processes, vacuolations in the granular and molecular layers, with gliosis and cell death which showed incomplete restoration of the normal structure of the cerebellar cortex upon stoppage ${ }^{21}$. The observed vacuolation and neuronal loss in the cortical layers of the RS group may adversely affect cerebellar function ${ }^{22}$.

\section{Conclusion}

This study shows that DS may have adverse effect on the histology of the cerebellum of female albino wistar rats; hence its consumption should be in minimal quantity.

\section{References}

1. Malik VS, Schulze MB, Hu FB. Intake of sugarsweetened beverages and weight gain: a systematic review. American Journal of Clinical Nutrition 2006; 84 (2): 274-328.

2. Vartanian LR, Schwartz MB, Brownell KD. Effects of soft drink consumption on nutrition and health: a systematic review and meta-analysis. American Journal of Public Health 2007; 97 (4): $667-$ 675.

3. Leif GT, Barnard RJ. An analysis of FDA passive Surveillance reports of seizures associated with consumption aspartame. Jamaican Dietary Association 1992; 72(5): 598-601.

4. Posch L, Vences M. The effect of aspartame on rat brain xenobiotic metabolizing enzymes. Hum Exp Toxicology 2007; 25 (25); 453-459.

5. Roberts HJ. Direct and indirect cellular effects as aspartame on the brain. Eur J Clin Nutr 1992; 62 (4): 451-462.

6. Ebbeling CB, Feldman HA, Osganian SK, Chomitz VR, Ellenbogen SJ, Ludwig DS. Effects of decreasing sugar-sweetened beverage consumption on body weight in adolescents: A 
randomized, controlled pilot study. Pediatrics 2006; 117(3): 673-680.

7. Humphries P, Pretorius E, Naude H. Direct and indirect cellular effects of aspartame on the brain. Eur J Clin Nutri 2008; 62 (4): 451-462.

8. Olney JW, Farber NB, Spitznagel E, Robins LN. Increasing brain tumor rates: is there a link to aspartame. J Neuropathol Exp Neurol 1996; 55(11): 1115-1123.

9. Tollefson L, Barnard RJ. An analysis of FDA passive Surveillance reports of seizures associated with consumption of aspartame. J Am Diet Association 1992; 1 (5): 598-601.

10. Ekong MB. Aspartame: sweet or bitter. The Internet Journal of Health. 2009; 9 (1)

11. Magnuson BA, Burdock GA, Doull J, Kroes RM, Marsh GM, Pariza MW, Spencer PS, Waddel WJ, Walker R, Williams GM. Aspartame: of safety evaluation based on current use levels, regulations and toxicological and epidemiological studies. 2007.

12. Gartner LP, Hiatt JL. Color Textbook of Histology, 2nd ed. New York: Saunders. 2001.

13. Koeppe RA, Shulkin BL, Rosenspire KC, Shaw LA, Betz AL, Mangner T, Price JC and Agranoff BW. Effect of aspartame-derived phenylalanine on neutral amino acid uptake in human brain: A positron emission tomography study. J. Neurochem 1991; 56(5):1526-1535.

14. Coulombe RA, Sharma RP. Neurobiochemical alterations induced by artificial sweetener aspartame $\{$ Nutrasweet\}. Toxicol Appl Pharmacol 1986; 83(1):79-85.

15. Holten AT, Gunderson V. Glutamine as a precursor for transmitter glutamate, aspartate and GABA in cerebellum: a role for phosphateactivated glutaminase. J Neurochem 2008; 104(4):1032-1042.
16. Pan HH, Suda Y, Ohe Y, Sumi M, Yoshioka M. Effect of aspartame on Nmethyl- D-aspartatesensitive L- $[3 \mathrm{H}]$ glutamate binding sites in rat brain synaptic membranes. Brain Res 1990; 520 (1-2): 351-353.

17. Christian B, McConnaughey K, Bethea E, Brantley S, Coffey A, Hammond L, Harrell S, Metcalf K, Muehlenbein D, Spruill W, Brinson L, McConnaughey M. Chronic aspartame affects Tmaze performance, brain cholinergic receptors and $\mathrm{Na}+, \mathrm{K}+-$ ATPase in rats. Pharmacol Biochem Behav 2004; 78(1): 121-127.

18. Llinas RRK, Walton D, Lang EJ. Cerebellum. In: The Synaptic Organization of the Brain, Shepherd GM, (ed) New York: Oxford University Press. 2004.

19. Brace H, Latimer M, Winn P. Neurotoxicity, blood barrier breakdown, demyelinization and remyelination associated with NMDA-induced lesions of the rat lateral hypothalamus. Brain Res Bull 1997; 43 (5): 447-455.

20. Lutsey P, Steffen L, Stevens J. Dietary intake and the development of the metabolic syndrome: the atherosclerosis risk in communities study. Circulation 2008; 117: 754-761.

21. Abd El-Samad AA. Light and electron microscopic study on the effect of aspartame on the cerebellar cortex of male albino rat. Egypt J Histol 2010; 33(3): 419-430

22. Ajibade AJ, Fakunle PB, Shallie PD. Some histological observation and microstructural changes in the Nissl substances in the cerebellar cortex of adult albino Wistar rats following artesunate administration. 2006. 